\title{
Species abundance distribution of benthic chironomids and other macroinvertebrates across different levels of pollution in streams
}

\author{
Hongqu Tang ${ }^{1}$, Mi-Young Song ${ }^{2}$, Woon-Seok Cho ${ }^{1}$, Young-Seuk Park ${ }^{3}$ and Tae-Soo Chon ${ }^{1 *}$ \\ ${ }_{1}$ Department of Biological Sciences, Pusan National University, Busan (Pusan) 609-735, Republic of Korea \\ 2 West Sea Fisheries Research Institute, Incheon 400-420, Republic of Korea \\ ${ }^{3}$ Department of Biology, Kyung Hee University, Dongdaemun, Seoul 130-701, Republic of Korea
}

Received 22 October 2009; Accepted 4 November 2009

\begin{abstract}
Chironomid assemblages collected from seven different streams in South Korea were investigated. The subfamily composition of chironomids was clearly differentiated accross different levels of organic pollution. Species abundance distributions (SADs) of chironomid communities were compared with the total macroinvertebrate communities across different levels of pollution. The number of species with minimal range of abundance was lower in SADs for chironomid communities compared with total communities. The log normal distribution was accepted for both total and chironomid communities, while the geometric series was relatively more suitable for chironomids and the log series were more fitted to total communities. The $a$ values in the log normal distribution increased in chironomid communities across different levels of pollution, while $\gamma$ values increased at the polluted sites for both chironomid and total communities. In the Power law analysis, the parameter decreased in chironomid communities. The dominance decay model was more fitted to chironomid communities in clean conditions while random fraction and assortment models were more suitable for the polluted sites.
\end{abstract}

Key words: Chironomid / species abundance distribution / macroinvertebrates / log normal distribution / power law analysis / random fraction / random assortment / dominance decay

\section{Introduction}

The family Chironomidae (Diptera) is a conspicuous component of freshwater communities, where they often exhibit high diversities and abundances (Resh and Rosenberg, 1984; Pinder, 1986; Armitage et al., 1995; Raposeiro et al., 2009). Chironomids thus make a significant contribution to community diversity at any sampling site. Consequently, they have been proposed as relevant water quality indicators, and are likely to be as sensitive as (or even more sensitive than) other biological indicators such as the well-known EPT (the species richness of Ephemeroptera, Plecoptera and Trichoptera), Ephemeroptera or Trichoptera taxa, Oligochaeta abundance, etc. (Saether, 1979; Resh and Jackson, 1993; Rosenberg, 1993; Barbour et al., 1996, 1999; De Bisthoven et al., 2005; Arimoro et al., 2007; Carew et al., 2007). Although some methods have been proposed for running waters (Schmid, 1992; Ruse, 1995; Lods-Crozet et al., 2001; Calle-Martinez

\footnotetext{
* Corresponding author: tschon@pusan.ac.kr
}

and Casas, 2006; Rossaro et al., 2006), previous bioassessment methods based on chironomids were mostly developed for lentic ecosystems such as lakes or reservoirs (Saether, 1979; Wiederholm, 1980; Aagaard, 1986; Rossaro et al., 2007; Hamerlik and Bitusik, 2009). Species abundance patterns deserve special attention when dealing with the structural response of communities to disturbances. Since Chironomidae colonize a very wide range of habitats, and all functional feeding groups are found within the family (Armitage et al., 1995), community patterns in Chironomidae such as species abundance distributions (SADs) could provide useful information for characterizing community responses to stressful conditions in aquatic ecosystems.

Since SADs have been studied by Raunkiaer (1909) and Motomura (1932), numerous research have dealt with various taxa representing marine communities (Gray and Mirza, 1979; Gray, 1981; Hughes, 1984; Magurran and Henderson, 2003), terrestrial plants (del Moral, 1999; Begon et al., 2006; Forster and Warton, 2007) and terrestrial animals (Fisher et al., 1943; Syrek et al., 2006; Ford 
and Lancaster, 2007). Extensive reviews can also be found in May (1975), Tokeshi (1993), Magurran (2004), May et al. (2007), and McGill et al. (2007).

Regarding chironomid communities, various SAD models have been proposed by Tokeshi (1990, 1993, 1995, 1999), who reported that the random fraction and assortment models were successfully fitted to the chironomid communities based on individual data (Tokeshi, 1990). Using chironomids collected from a large river, Fesl (2002) reported that the observed communities did not fit the various niche-oriented models including the geometric series, whereas the distribution of functional feeding groups in chironomids fitted the random fraction model. In contrast, Ruse (1995) found that the abundance patterns of larval and pupal chironomids from a chalk stream were best described by a log series model. Alternatively, Dimitriadis and Cranston (2007) studied estuarial systems, where abundance patterns of chironomid communities fitted geometric series. SADs were also checked for different life stages. Boerger (1981) collected emerging chironomids from a muskeg stream and reported there were more rare species than expected from Preston's lognormal distribution, while the community pattern, excluding the rare species, did not differ significantly from the log normal model.

Earlier studies on SADs in chironomids have considered the impact of different stream types, covering unpolluted (Schmid, 1992; Ruse, 1995), muskeg (Boerger, 1981) and estuarial (Dimitriadis and Cranston, 2007) ecosystems. Previous research has been also carried out at sites under stressful conditions subjected to organic pollution (Calle-Martinez and Casas, 2006), or sediment clogging (Carew et al., 2007) and river regulation (Penczak et al., 2006). However, these studies mostly aimed at defining indicator groups for a selected range of disturbances (Saether, 1975, 1979; Wiederholm, 1980; Rossaro et al., 2006). No extensive analysis has examined the SADs of chironomids in response to organic pollution, in comparison with total benthic macroinvertebrates. Dimitriadis and Cranston (2007) recently checked the SADs of Chironomidae exposed to a salinity gradient, and reported an overall satisfactory fit was achieved with the geometric series. Recently, the SADs of total benthic macroinvertebrates in polluted streams were evaluated by $\mathrm{Qu}$ et al. (2008), who found that the SADs were useful for depicting the ecological status of the sampling sites. As a continuation of this study, we investigated the SADs in chironomid communities and compared them with the structural properties of the total communities across different levels of pollution.

\section{Materials and methods}

\section{Study area}

Data sets were built upon benthic macroinvertebrates collected at the 14 sampling sites in six streams (Main channel in the Nakdong River Basin, and streams of
Baenae, Daechon, Onchon, Hakjang, and Kumsan), including one large (Nakdong) and two short (Suyong and Kumsan) river basins in Korea from 2004 to 2008 (Fig. 1, Table 1). The sampling sites represented different levels of pollution (Table 1). An unpolluted site (B; BCN) was selected from the Baenae Stream, a tributary located in the middle course of the Nakdong River Basin. The Baenae stream is located in a mountainous area (Fig. 1) and is relatively unpolluted (see Table 1). However, due to an increase in summer tourism since the 1990's there has been a corollary increase in the level of disturbance ( $\mathrm{Oh}$ and Chon, 1991a, 1991b, 1993).

The Keumsan stream (three successive sites; S1(KBK), S2(KMI), S3(KUP)) also located in a mountainous area was additionally selected to represent unpolluted conditions (Fig. 1). The Onchon stream originates in a mountainous area and passes through a residential area (Kwak et al., 2002), thus presenting a range of unpolluted (O1; OCU) to polluted sites (O2; ONS) (Table 1). Since the early $2000 \mathrm{~s}$, a recovery project has been conducted by the local government in this stream.

The Daechon Stream was selected to reflect the impact of different levels of organic pollution. It is a tributary of Nakdong River Basin that passes through a mountainous area. The middle section of the stream has been heavily polluted by the many restaurants in the area. Two sites (D2 (DDK) and D3 (DKS)) were polluted by domestic sewage (Song et al., 2005; Qu et al., 2008), while D1 (DUK) was unpolluted in the upstream area. The site D4 (DAG), located further downstream from D2 and D3 (Fig. 1), showed a recovering status (see Table 1).

Two streams were selected to represent polluted and severely polluted sites. Four sampling sites (N1 (NSJ), N2 (NKJ), N3 (NJP), and N4 (NMK)) located in the main stream of the Nakdong River Basin represented the polluted state (Table 1). The sampling sites were located in the lower river basin in suburban area. Along with the sampling site in the Baenae Stream, the sample sites in the main channel of the Nakdong River have been surveyed for the national LTER (Long-Term Ecological Research Project in Korea) since 2005.

The Hakjang Stream in the Nakdong River Basin is a tributary of the Nakdong River Basin within Busan city and was selected to represent severe pollution. The site $\mathrm{K}$ (HJD) in the Hakjang Stream has been heavily affected by domestic and industrial pollution (see BOD and BMWP values in Table 1). The sampling procedure details were summarized in Table 2. Seasonal samplings were carried out from winter 2004 to spring 2007 in the Daechon and Onchon Streams, while monthly samplings were conducted at sites B, N1 and N2 from March 2005 to August 2008. In total, 176 samples were analysed.

\section{Community data}

Benthic macroinvertebrates including chironomids were collected using a Surber net (sampling area $=30 \times$ $30 \mathrm{~cm}^{2}$, mesh size $\left.=100 \mu \mathrm{m}\right)$. Three collections mainly 


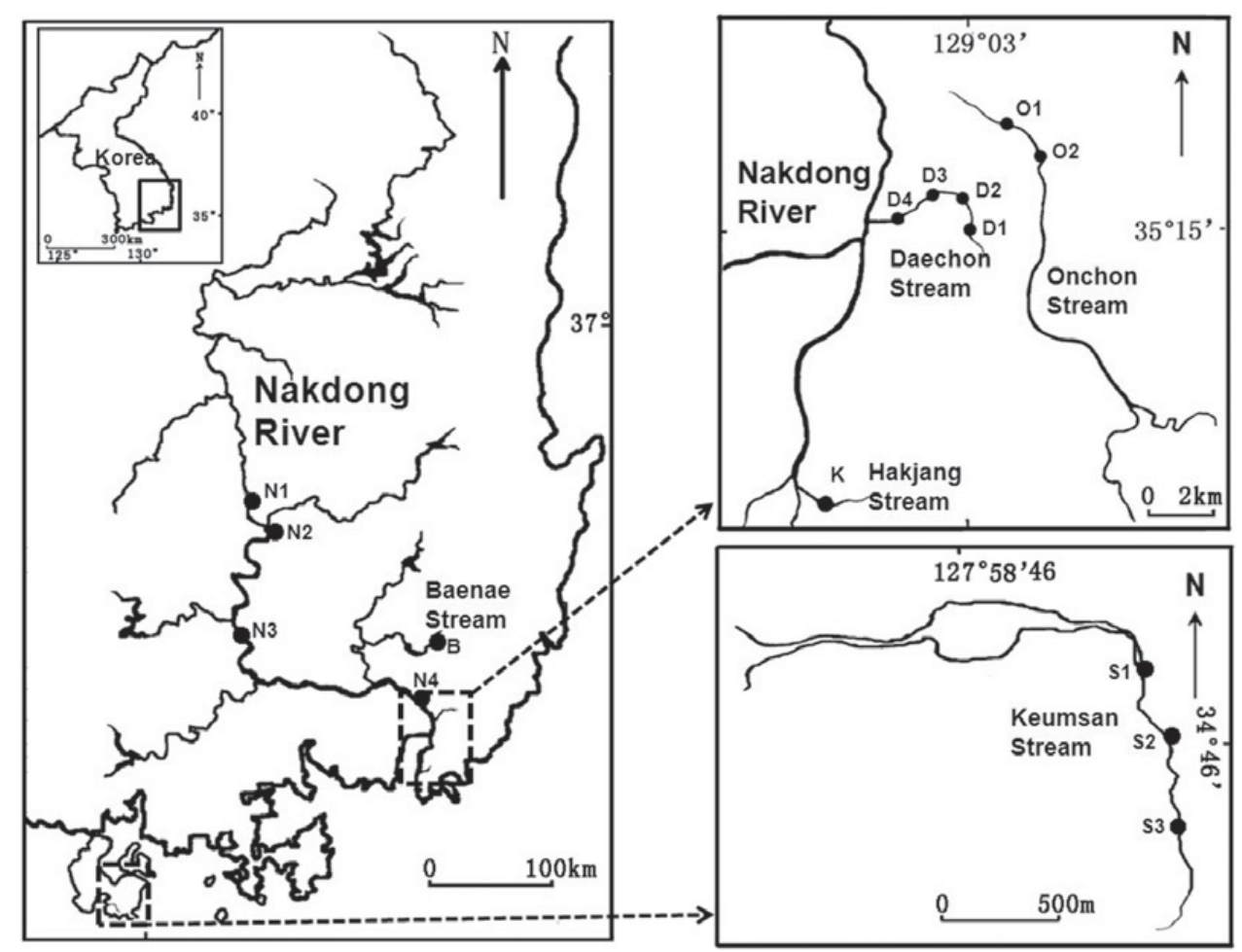

Fig. 1. Location of sample sites in different streams in Korea.

Table 1. Environmental factors, Biological Monitoring Working Party (BMWP), and pollution states at the sample sites.

\begin{tabular}{|c|c|c|c|c|c|c|}
\hline Streams & Sites & BOD (mg.L $\left.{ }^{-1}\right)$ & Turbidity (NTU) & Conductivity $\left(\mu \mathrm{S} . \mathrm{cm}^{-1}\right)$ & BMWP* & Pollution level \\
\hline Baenae & $\mathrm{B}$ & $1.15 \pm 0.80$ & $0.84 \pm 0.95$ & $23.86 \pm 6.66$ & $121(68-157)$ & Low \\
\hline \multirow[t]{3}{*}{ Keumsan } & S1 & $2.23 \pm 0.25$ & $0.65 \pm 0.39$ & $31.79 \pm 14.69$ & $111(87-131)$ & Low \\
\hline & $\mathrm{S} 2$ & $3.41 \pm 1.60$ & $0.69 \pm 0.70$ & $48.06 \pm 29.76$ & $121(96-162)$ & Low \\
\hline & S3 & $3.17 \pm 0.51$ & $1.11 \pm 1.60$ & $33.00 \pm 20.37$ & $111(93-130)$ & Low \\
\hline \multirow[t]{4}{*}{ Daechon } & D1 & $2.02 \pm 2.34$ & $5.54 \pm 8.54$ & $41.36 \pm 7.66$ & $110(61-180)$ & Low \\
\hline & D2 & $6.88 \pm 5.68$ & $4.16 \pm 3.97$ & $176.76 \pm 73.21$ & $37(17-52)$ & Intermediate \\
\hline & D3 & $4.52 \pm 3.36$ & $2.87 \pm 2.31$ & $211.90 \pm 97.31$ & $43(15-76)$ & Intermediate \\
\hline & D4 & $2.56 \pm 1.63$ & $0.96 \pm 0.78$ & $161.03 \pm 75.16$ & $76(44-116)$ & Intermediate \\
\hline \multirow[t]{2}{*}{ Onchon } & $\mathrm{O} 1$ & $2.75 \pm 1.70$ & $2.43 \pm 1.31$ & $72.82 \pm 43.29$ & $128(95-162)$ & Low \\
\hline & $\mathrm{O} 2$ & $3.78 \pm 2.68$ & $7.72 \pm 10.41$ & $237.51 \pm 147.3$ & $41(24-54)$ & Intermediate \\
\hline \multirow[t]{4}{*}{ Nakdong } & N1 & $9.84 \pm 4.75$ & $12.01 \pm 10.28$ & $311.95 \pm 56.21$ & $52(20-75)$ & High \\
\hline & $\mathrm{N} 2$ & $8.70 \pm 5.49$ & $10.90 \pm 12.01$ & $316.25 \pm 64.73$ & $40(35-50)$ & High \\
\hline & N3 & $7.38 \pm 6.81$ & $10.03 \pm 6.21$ & $452.25 \pm 107.17$ & $53(30-82)$ & High \\
\hline & N4 & $8.89 \pm 6.64$ & $17.61 \pm 26.42$ & $329.29 \pm 120.78$ & $26(7-50)$ & High \\
\hline Hakjang & $\mathrm{K}$ & $31.80 \pm 23.86$ & $12.92 \pm 9.03$ & $480.44 \pm 189.20$ & $19(9-36)$ & Extreme \\
\hline
\end{tabular}

* Number in parenthesis is range.

covering riffle zones were conducted as replicates at each site. Chironomid samples were sorted from the benthic macroinvertebrates and preserved in $85 \%$ alcohol in the laboratory. The larvae were further hand sorted under a stereo-microscope and counted separately. For coarse identification, sorted individuals were classified into several possible species groups based on similar morphological characters; such as body seta, body color, body shape, the location of eye, etc. Subsequently, at least 1-5 individuals from each possible species groups were picked out and dissected into head and body to mount into slides by CMC-10 solution (Master Company, Inc., Illinois). Fine classification was conducted under the compound micro- scope by checking the mounted slides. In most cases the specimens were identified to species or to the lowest possible taxonomical level following the keys of Sasa (1979, 1984), Ree and Kim (1981), Cranston (1982), Wiederholm (1983, 1986), Sasa and Kikuchi (1995), Epler (2001), Klink and Moller Pillot (2003), Langton and Visser (2003), Wilson and Ruse (2005), Nittsuma and Yamamoto (2005) and Tang (2006). Part of the adult samples collected by sweep net or reared in the lab and the pupal samples collected at the same place were further used to confirm the larval status.

As many researchers have mentioned, classification of all collected larvae is practically impossible (Kawai et al., 
Table 2. Sampling methods and description of the sample areas.

\begin{tabular}{llclrl}
\hline Streams & Sites & Sampling frequency & Sampling periods & No. of samples & Area \\
\hline Baenae & B & Monthly & May., 05-Aug., 08 & 31 & Mountain \\
Keumsan & S1 & Seasonal & Spr., 07-Aug., 08 & 7 & Mountain \\
& S2 & Seasonal & & 7 & Mountain \\
Daechon & S3 & Seasonal & Win., 04-Spr., 07 & 11 & Mountain \\
& D1 & Seasonal & & 11 & Residence/Mountain \\
& D2 & Seasonal & & 11 & Residence/Mountain \\
& D3 & Seasonal & & 11 & Residence/Mountain \\
Onchon & D4 & Seasonal & Win., 04-Spr., 07 & 11 & Residence/Mountain \\
& O1 & Seasonal & & 11 & Mountain \\
Nakdong & O2 & Seasonal & Mar., 05-Aug.,08 & 14 & Residence \\
& N1 & Monthly & Spr., 05-Spr., 06 & 4 & Suburban \\
& N2 & Seasonal & Spr., 05-Spr., 06 & 4 & Suburban \\
Hakjang & N3 & Seasonal & Mar., 05-Mar., 08 & 25 & Suburban \\
\end{tabular}

1989; Rabeni and Wang, 2001), since there are numerous specimens with small-sized individuals. Subsampling was conducted if the number of individuals of some samples exceeded 300, according to Barbour et al. (1999). In each subsample, 100-300 individuals were identified for this study.

A biological index, the revised BMWP (Hawkes, 1997), was used to characterize the sites according to the identified communities. Environmental variables were also measured at each sampling time during the collection of communities. Water temperature $\left({ }^{\circ} \mathrm{C}\right)$, dissolved oxygen $\left(\mathrm{DO}, \mathrm{mg} . \mathrm{L}^{-1}\right)$, conductivity $\left(\mu \mathrm{S} . \mathrm{cm}^{-1}\right)$, turbidity and other environmental factors were measured in situ with multifunction probes. BOD $_{5}$ was checked according to Standard Methods (APHA, AWWA and WPCF, 1985).

\section{Data analysis - Species abundance distribution (SAD)}

Considering that not all small chironomid larvae can be identified, we chose models that are robust when dealing with missing rare species. In this regard the log normal distribution (Preston, 1948; May, 1975) and the power law (Pueyo, 2006b) were used for analysis. The truncated log normal distribution assumes that rare species are not fully surveyed during the sampling, and the model would show a truncated pattern in the lower side of octaves in abundance (Preston, 1948; May, 1975; Magurran, 2004). Consequently, this model could be applicable when small and rare species are not extensively collected.

The log normal distribution (Preston, 1948; May, 1975) presents frequency of species arranged on the logarithm scale of species abundance in the normal distribution:

$$
S(R)=S_{0} \exp \left(-a^{2} R^{2}\right)
$$

where $S(R)$ is the number of species in the Rth octave (i.e. class) in abundance to the right and left of the symmetrical curve and $S_{0}$ is the number of species in the modal octave. Parameter $a$ indicates the inverse width of the distribution: $a=\left(2 \sigma^{2}\right)^{-1 / 2}$ where $\sigma$ is the standard deviation of the observed values after taking the logarithm (Preston, 1948; May, 1975). In this study, the truncated log normal distribution was used to fit the community data based on Magurran (2004). After estimation of the parameters, the Kolmogorov-Smirnov test (Sokal and Rohlf, 1995) was used to check fitness of field data in the benthic invertebrate communities (Qu et al., 2008).

The universality residing in the power law has been demonstrated to reveal structural properties in the sampled communities. In the power law analysis, the slopes between species and log abundance could be represented by excluding the maximal or minimal ranges in abundance (Pueyo, 2006b). The power law is based on the following relationship (Pueyo, 2006a, 2006b):

$$
p(n) \propto n^{-\beta}
$$

where $p(n)$ is the probability density of $n$ individuals in communities, and $\beta$ is a constant. According to Pueyo (2006b), $p(n)$ is replaced with $f(n)$ as a continuum of probability densities, and the value in each bin $j$ was estimated in our study as:

$$
f\left(n_{j}\right)=\frac{1}{2^{j}} \frac{s_{j}}{S}
$$

where $s_{j}$ is the number of species in bin $j$ for the abundance class (in this case, interval $=2$ ), $2^{j}$ indicates the width of bin $j$, and $S$ is the total number of species. For each bin $j$ the (logarithmically) central value is $n_{j}=2^{j+\frac{1}{2}}$. The maximum likelihood estimation was used to estimate the $\beta$ values. The detailed method can be found in Pueyo (2006b) and Qu et al. (2008).

Two other traditional models widely used in analyzing SADs are the geometric and log series. We also checked the models for comparative purposes. In the geometric series species abundance, ranked from most to least abundant, is expressed as (Motomura, 1932; May, 1975; Magurran, 1988, 2004):

$$
n_{i}=N C_{k}(1-k)^{i-1}
$$

where $n_{i}$ is the number of individuals in the $i$ th species, $k$ is the proportion of the available resource that each species 
Table 3. The chironomid subfamilies/tribes composition across different levels of pollution.

\begin{tabular}{|c|c|c|c|c|c|c|c|c|}
\hline \multirow[b]{2}{*}{$\begin{array}{l}\text { Pollution } \\
\text { level }\end{array}$} & \multicolumn{5}{|c|}{ Subfamilies $(\%)^{*}$} & \multicolumn{3}{|c|}{ Dominant species } \\
\hline & $\begin{array}{c}\text { Podo. } \\
\%\end{array}$ & $\begin{array}{c}\text { Tany. } \\
\%\end{array}$ & $\begin{array}{c}\text { Diam. } \\
\%\end{array}$ & $\begin{array}{l}\text { Ortho. } \\
\%\end{array}$ & $\begin{array}{c}\text { Chiro. } \\
\%\end{array}$ & $1 \mathrm{st}$ & 2nd & $3 \mathrm{rd}$ \\
\hline Low & 0.09 & 9.38 & 0.14 & 46.13 & 44.26 & Tanytarsus brundini & Parametriocnemus stylatus & Polypedilum surugen \\
\hline $\begin{array}{l}\text { Inter- } \\
\text { mediate }\end{array}$ & 0 & 7.43 & 4.72 & 50.02 & 37.83 & Chironomus flaviplumus & Micropsectra atrofasciatus & $\begin{array}{l}\text { Orthocladius } \\
\text { yugashimaensis }\end{array}$ \\
\hline High & 0 & 2.75 & 1.06 & 36.43 & 59.76 & Cricotopus triannulatus & Polypedilum cultellatum & Tanytarsus mendax \\
\hline Extreme & 0 & 0 & 0 & 3.93 & 96.07 & Chironomus flaviplumus & Paratrichocladius rufiventris & - \\
\hline
\end{tabular}

* Podo.: Podonominae, Tany.: Tanypodinae, Diam.: Diamesinae, Ortho.: Orthocladiinae, Chiro.: Chironominae.

utilizes, $N$ is the total number of individuals, and $C_{k}$ is a constant ensuring $\sum n_{i}=N$ (see Magurran, 2004).

The $\log$ series originally proposed by Fisher et al. (1943) is presented as:

$$
\alpha x, \frac{\alpha x^{2}}{2}, \frac{\alpha x^{3}}{3}, \ldots, \frac{\alpha x^{n}}{n}
$$

where $\alpha$ is the index of diversity, $n$ is species sequence from the minimum to the maximum, and $x$ is estimated from the iterative solution of $S / N=(1-x) / x[-\ln (1-x)]$ ( $S$, the total number of species, and $N$, the total number of individuals).

The SAD models proposed for Chironomidae (Tokeshi and Townsend, 1987; Tokeshi, 1990) were also tested using the chironomids sampled in this study. The random fraction (RF) model was the basic concept for this type of model, and various models were subsequently created to accommodate diverse situations in niche preemption. In the RF model all species in an assemblage have the same probability of being selected for subsequent niche division by other invading species. The niche is first divided at random into two fractions, one of which is randomly chosen and divided at random into further two fractions. This type of fractioning continues to produce more fractions until niche space for the species with the lowest rank is formed (Tokeshi, 1990). The random assortment model (RF) refers to a situation where abundances of different species are not mutually related. Niche space is restricted in size only by its immediate, larger neighbor on the niche-rank axis. This relationship can be expressed as:

$$
\begin{aligned}
& N_{i}=1 \\
& N_{i}=r_{i} N_{i-1}(i, \text { integer greater than } 1)
\end{aligned}
$$

where $N_{i}$ is the niche size (abundance) of rank $i$ and $r_{i}$ is an independent uniform random variable between 0 and 1 (Tokeshi, 1990).

The dominance decay (DD) model refers to a situation where new species always take a portion of niche space already occupied by the most dominant species (Fesl, 2002). Consequently the model is conducted toward the negation of dominance and converges towards equitable abundances of constituent species (Tokeshi, 1990).

The RF, RA and DD models were applied to the field data. For fitting the models to the field data, 10000 assemblages were simulated in accordance with the number of species collected in the field. The $95 \%$ confidence limits were obtained from the simulation models and were used for checking the field data. The detailed method can be found in Tokeshi (1990), Fesl (2002) and Magurran (2004).

\section{Results}

\section{Composition of chironomid communities}

In total, 85 chironomid species were collected during the survey periods, including one species from the subfamily Podonominae, nine Tanypodinae, four Diamesinae, 36 Orthocladiinae, and 35 Chironominae. Subfamily composition was clearly differentiated across the various levels of pollution (Table 3). At the unpolluted sites, Orthocladiinae were most dominant, followed by Chironominae. This was contrasted with the polluted sample sites, where Chironominae were distinctively dominant. At the severely polluted site, Chironominae abundance was extremely high $(>96.7 \%$ ), while dominance of Chironominae decreased to $59.8 \%$, followed by Orthocladinae with $36.4 \%$ at the highly polluted sites (Table 3 ). At sites with intermediate levels of pollution Orthocladiinae were the most dominant followed by Chironominae, which was similar to the case of unpolluted sites (Table 3). Tanypodinae and Podonomiinae were present at low densities across the different levels of pollution during the study periods.

Dominant species were variable with different levels of pollution (Table 3). Sites with low levels of pollution, for instance, were characterized by the following dominant species: Tanytarsus brundini, Parametriocnemus stylatus and Polypedilum surugense. Cricotopus triannulatus, Polypedilum cultellatum and Tanytarsus mendax were dominant at sites with high levels of pollution. At the most severely polluted site, K, Chironomus flaviplumus and Paratrichocladius rufiverntris were selectively dominant.

Figure 2 outlines species richness for all species, the chironomid, and EPT (Ephemeroptera, Plecoptera and Trichoptera) communities across the different levels of pollution. The sample sites were arranged according to the order of total species richness from left to right in the figure. The first group in the left-hand side of Figure 2, from site O1 to D4 (unpolluted state) showed the highest total species richness at close to 40 . Species richness in chironomids was a little over 10. A substantial EPT 


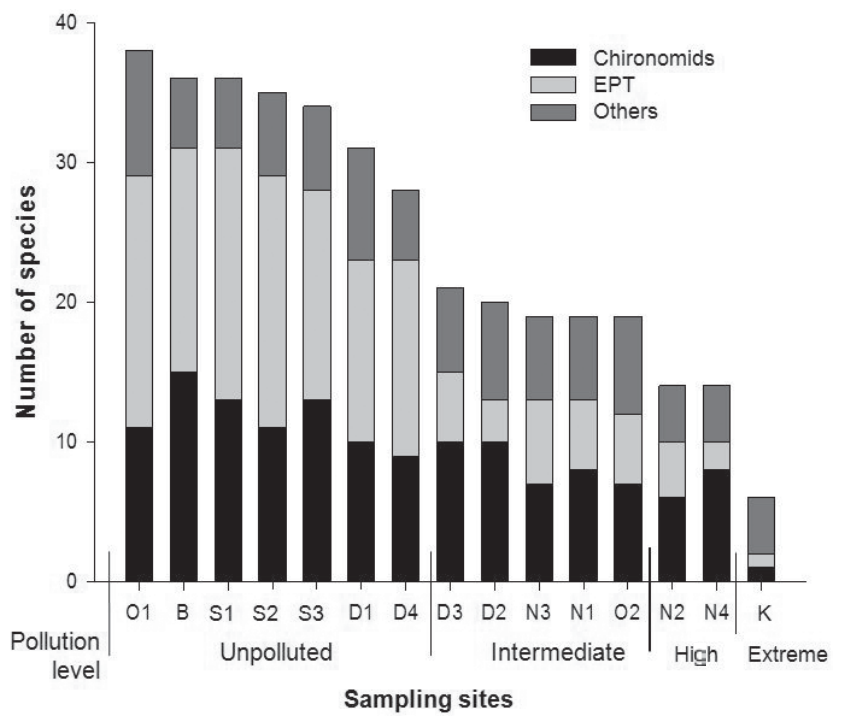

Fig. 2. The number of species collected in total, chironomid and EPT across different levels of pollution (monthly averages).

richness was observed in this group. The number of species was a little higher (15-20) than for chironomids.

The second group of sites, with intermediate pollution, showed a lower species richness in total communities, with around 20 species. The number of chironomid species, however, remained around 10 . It was notable that EPT richness decreased substantially $(<5)$. The polluted sites showed lower species richness (around 15 species) and lower EPT richness (2-3). The decrease in species richness for total communities at the intermediately polluted sites was mainly caused by the decrease in EPT species.

At the polluted sites total species richness decreased further to around 10 on average. The number of chironomid species, however, was fairly stable from clean to polluted sites with around 10 species. At the extremely polluted site $(\mathrm{K})$, located in the far right-hand side of Figure 2, richness decreased greatly to a minimum of seven species. Chironomid richness also decreased to three species, and only a few EPT species were collected.

\subsection{SADs in total and chironomid communities}

SAD was compared between chironomid and total macroinvertebrate communities. The number of species was presented according to the individuals in the octaves using $\log _{2}$ for both total benthic macroinvertebrates and chironomids (Fig. 3). The patterns between the two communities were characteristically different. For the total communities, most curves showed truncated patterns at the unpolluted sites: relatively higher levels of the number of species were observed at the minimal range of octaves (the far left hand side of the plots in Fig. 3). At the intermediately polluted sites, however, the truncated pattern was not clear, and the number of species was mostly in the maximal range at the minimum level of the octaves (i.e., left hand side of the figure) (e.g., N1-N4 in Fig. 3).
In chironomids, however, the SADs were substantially different from the total communities (Fig. 3). The truncated patterns were usually not observed: the minimal number of species was found at the minimal range of octaves. The number of species gradually increased with the increasing level of octaves, and subsequently decreased after the level of octaves reached the peak in the middle area of the octaves. These patterns in chironomids were similarly observed across the different levels of pollution, although the height of peaks tended to decrease for the polluted sites. At the extremely polluted site, $\mathrm{K}$, this trend was not observed for chironomids. Only three species were recorded at this site.

\section{Model fitting}

When the log normal model was applied to total communities and to chironomid communities according to Magurran (2004), all samples were statistically fitted to this model for both total and chironomid communities (Table 4). The other models, however, were selectively accepted. The geometric series was mostly rejected using samples from total communities, while the model was mostly accepted using the chironomid communities across the different levels of pollution. The log series showed the reverse situation: the model was mostly rejected for the chironomid communities while the model was accepted using the majority of the total communities (Table 4). It was notable that the severely $(\mathrm{K})$ and highly polluted (e.g., D2-D3, N1-N4) sites were not acceptable using the geometric series for the total communities. This study, however, further showed that the geometric series was fitted to the chironomid communities.

The parameters $a$ and $\gamma$ in the log normal distribution were also obtained across different levels of pollution (Table 5). The $a$ and $\gamma$ values were in the range around 0.2 $(0.175-0.291)$ and $1.0(0.672-1.207)$ respectively (Table 5$)$. In chironomid communities the $a$ values were consistently higher than in the total communities across different levels of pollution ranging from $0.146-0.377$. The parameter $a$ represents inverse of width of distribution $\left(a=\left(2 \sigma^{2}\right)^{-1 / 2}\right)$ (May, 1975; May and McLean, 2007). The increase in $a$ values reflected that the chironomid communities had a relative low range in distribution of the octaves.

In both total and chironomid communities, however, the $a$ values did not show differentiation in responding to different levels of pollution. However, the severely polluted site (e.g., K; 0.175) showed the lowest value. The occurrence of the low value for this site would be exceptional since the level of species richness was extremely low (Fig. 3).

In contrast to the $a$ values, the $\gamma$ values differed according to the different levels of pollution. In total communities, the $\gamma$ values tended to increase from unpolluted (e.g. Baenae Stream, Keumsan Stream, O1 in Onchon stream; 0.707-0.853) to polluted sites (e.g., Hakjang Stream, Main stream in the Nakdong River Basin, D2 and D3; 0.755-1.207) (Table 5). The increase in the 


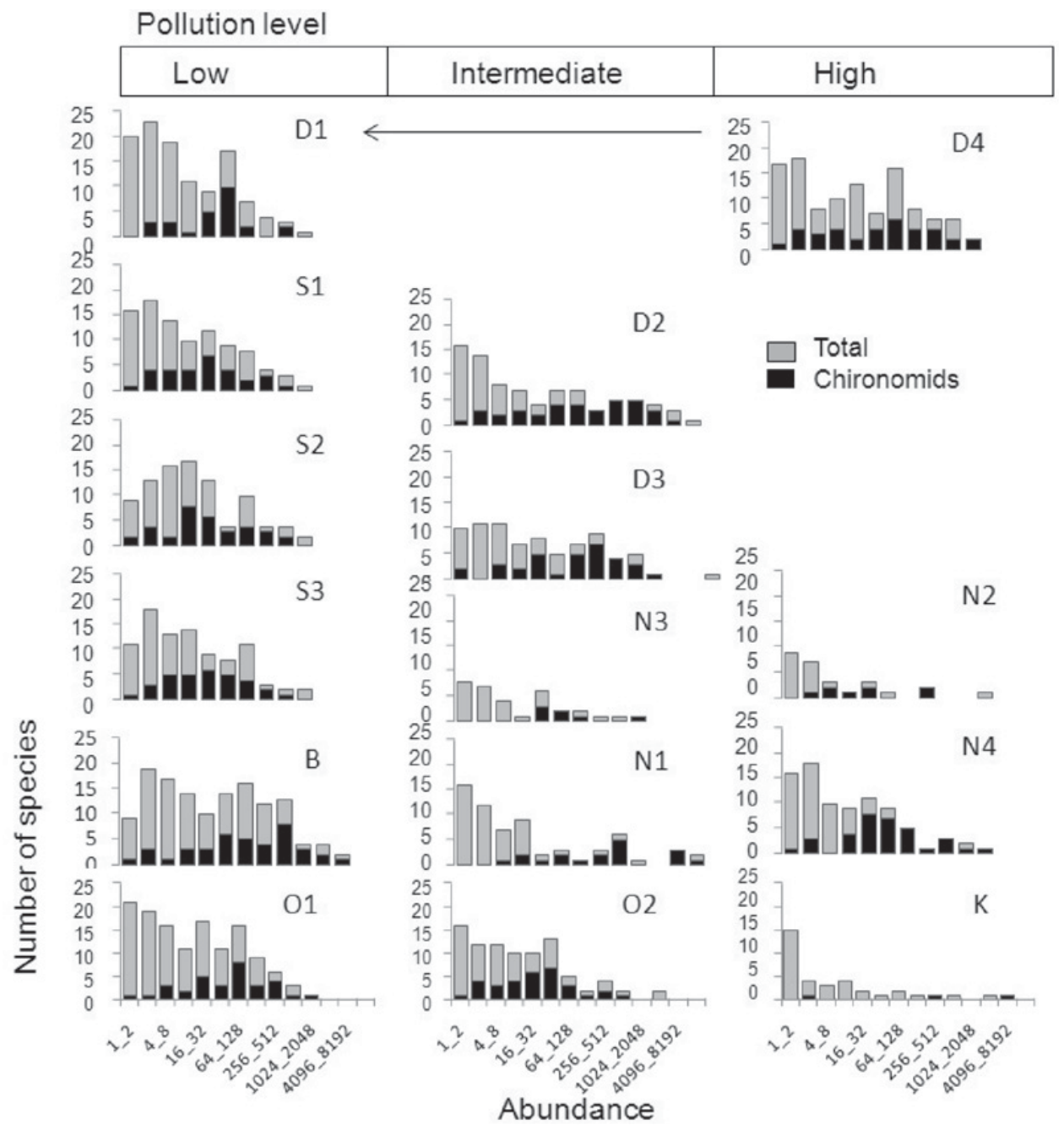

Fig. 3. The number of species related to abundance in octaves for total and chironomid communities across different levels of pollution in streams.

Table 4. Statistical values of Kolmogorov-Smirnov test for goodness of fit for the SAD models applied to total and chironomid communities.

\begin{tabular}{|c|c|c|c|c|c|c|c|}
\hline \multirow[b]{2}{*}{ Streams } & \multirow[b]{2}{*}{ Sites } & \multicolumn{2}{|c|}{ Log normal } & \multicolumn{2}{|c|}{ Geometric series } & \multicolumn{2}{|c|}{ Log series } \\
\hline & & Total & Chironomid & Total & Chironomid & Total & Chironomid \\
\hline Baenae & $\mathrm{B}$ & 0.0575 & 0.0759 & $0.2028 * *$ & 0.0842 & 0.0409 & $0.2336^{* *}$ \\
\hline \multirow[t]{3}{*}{ Keumsan } & S1 & 0.0388 & 0.0823 & $0.2165 * *$ & 0.0427 & 0.0444 & $0.2043 * *$ \\
\hline & S2 & 0.0381 & 0.0758 & $0.2109 * *$ & 0.0766 & 0.0496 & $0.1929 * *$ \\
\hline & S3 & 0.0238 & 0.0392 & $0.2385 * *$ & 0.0949 & 0.0385 & $0.1839 *$ \\
\hline \multirow[t]{4}{*}{ Daechon } & D1 & 0.0380 & 0.0577 & $0.2770 * *$ & 0.1613 & 0.0723 & $0.3145^{* *}$ \\
\hline & D2 & 0.0510 & 0.0898 & $0.2020 * *$ & 0.1122 & $0.1024 *$ & $0.1980 * *$ \\
\hline & D3 & 0.0543 & 0.1453 & $0.5208 * *$ & $1.0001 * *$ & 0.0775 & $0.2470 * *$ \\
\hline & D4 & 0.0445 & 0.0947 & $0.1651 * *$ & 0.0383 & 0.0340 & $0.1579 *$ \\
\hline \multirow[t]{2}{*}{ Onchon } & $\mathrm{O} 1$ & 0.0354 & 0.0314 & $0.1787 * *$ & 0.0688 & 0.0235 & $0.2312 * *$ \\
\hline & $\mathrm{O} 2$ & 0.0243 & 0.0448 & $0.4288 * *$ & $0.1608^{*}$ & $0.1176^{* *}$ & 0.1536 \\
\hline \multirow[t]{4}{*}{ Nakdong } & N1 & 0.0690 & 0.0993 & $0.3649 * *$ & 0.0548 & $0.2363 * *$ & $0.2489 * *$ \\
\hline & N2 & 0.0733 & 0.2610 & $0.4954 * *$ & 0.0883 & $0.2703 * *$ & 0.1541 \\
\hline & N3 & 0.0633 & 0.2385 & $0.3361 * *$ & $0.3737 *$ & 0.0958 & $0.4884 * *$ \\
\hline & N4 & 0.0154 & 0.0780 & $0.3803 * *$ & 0.1269 & 0.0768 & $0.2640 * *$ \\
\hline Hakjang & $\mathrm{K}$ & 0.1094 & 0.4821 & $0.6146^{* * *}$ & 0.0228 & $0.3526 * *$ & 0.2774 \\
\hline
\end{tabular}

*Significant $(\alpha=0.05)$.

**Highly significant $(\alpha=0.01)$. 
Table 5. Parameters in the log normal distribution in total and chironomid communities in different streams.

\begin{tabular}{|c|c|c|c|c|c|c|c|}
\hline \multirow[b]{2}{*}{ Streams } & \multirow[b]{2}{*}{ Sites } & \multicolumn{3}{|c|}{ Total } & \multicolumn{3}{|c|}{ Chironomid } \\
\hline & & $D_{\max }$ & $a$ & $\gamma$ & $D_{\max }$ & $a$ & $\gamma$ \\
\hline Baenae & $\mathrm{B}$ & 0.0575 & 0.237 & 0.853 & 0.0759 & 0.254 & 0.947 \\
\hline \multirow[t]{4}{*}{ Keumsan } & S1 & 0.0388 & 0.285 & 0.716 & 0.0823 & 0.345 & 0.721 \\
\hline & $\mathrm{S} 2$ & 0.0381 & 0.285 & 0.722 & 0.0758 & 0.305 & 0.789 \\
\hline & S3 & 0.0238 & 0.288 & 0.707 & 0.0392 & 0.343 & 0.754 \\
\hline & $\mathrm{O} 1$ & 0.0354 & 0.254 & 0.781 & 0.0314 & 0.292 & 0.823 \\
\hline Onchon & $\mathrm{O} 2$ & 0.0243 & 0.250 & 0.834 & 0.0448 & 0.304 & 0.816 \\
\hline \multirow[t]{4}{*}{ Daechon } & D1 & 0.0380 & 0.291 & 0.672 & 0.0577 & 0.377 & 0.606 \\
\hline & D2 & 0.0510 & 0.192 & 1.083 & 0.0898 & 0.228 & 1.197 \\
\hline & D3 & 0.0543 & 0.222 & 1.010 & 0.1453 & 0.250 & 0.994 \\
\hline & D4 & 0.0445 & 0.229 & 0.890 & 0.0947 & 0.240 & 1.077 \\
\hline \multirow[t]{4}{*}{ Nakdong } & N1 & 0.0690 & 0.193 & 1.080 & 0.0993 & 0.245 & 1.114 \\
\hline & N2 & 0.0733 & 0.266 & 0.878 & 0.2610 & 0.324 & 1.284 \\
\hline & N3 & 0.0633 & 0.260 & 0.924 & 0.2385 & 0.410 & 0.806 \\
\hline & N4 & 0.0154 & 0.270 & 0.755 & 0.0780 & 0.305 & 0.787 \\
\hline Hakjang & K & 0.1094 & 0.175 & 1.207 & 0.4821 & 0.146 & - \\
\hline
\end{tabular}

$\gamma$ values at the polluted sites was also observed in chironomid communities (Table 5). For the clean sites the value ranged between $0.606-0.947$, while the values were higher at the polluted sites with a range from $0.787-1.284$. The $\gamma$ values $\left(R_{N} / R_{\max }\right)$ indicate the ratio of the octave for the most abundant species $\left(R_{\max }\right)$ in species curve and the modal octave $\left(R_{N}\right)$ in individual curve (May and McLean, 2007). While the $a$ values were higher for chironomids, the $\gamma$ values in chironomid communities were similar $(0.606$ $1.284)$ to the $\gamma$ values in total communities $(0.672-1.207)$.

\section{Power law analysis}

As stated previously, the power law as proposed by Puyeo (2006b) is robust in dealing with rare species. According to the maximum likelihood method, the $\beta$ values were generally in the higher range (1.29-1.49) for total benthic macroinvertebrate communities (Table 6). No clear difference was observed for the different levels of pollution. In chironomids, however, the values were consistently lower compared with the unpolluted sites, ranging from $0.87-1.27$ with the exception of one sampling site, N3. The low levels of slopes indicated that the proportion of the medium range in log abundance was relatively higher in chironomid communities. This is understandable when considering that the number of species was relatively higher in the mid range of the octaves in chironomids (Fig. 3). Similar to the case for the total communities, differences in the values was not clearly observed for different pollution levels for chironomid communities (Table 6).

At site $\mathrm{N} 3$ the $\beta$ value was exceptionally high at 1.61. This was due to the exceptional dominance by the selected chironomid species at site N3. The density of the primary dominant species was 781 individuals. $\mathrm{m}^{-2}$, while density of the secondary dominant species was exceptionally low at 76 individuals. $\mathrm{m}^{-2}$. The density of the least abundant species was also low at 19 individuals.m ${ }^{-2}$. This discrepancy in densities among species contributed to the increase in $\beta$ values at N3. Considering the field sampling conditions, this might be an exceptional case.

In fact, the $\beta$ values were exceptionally variable at sample sites in the main channel of the Nakdong River (site N1-N4). While the values were in the minimal range, between $0.87-0.93$ at site $\mathrm{N} 1$ and N2, the values at site N3 and N4 were maximal at $1.25-1.61$. This indicated that community structure was exceptionally variable in chironomid communities in this area compared with other areas.

The $\beta$ values calculated from the linear regression appeared to decrease slightly for both chironomid and total communities when compared to values obtained from the maximum likelihood estimation (Table 6). The variability in the values among the sample sites was similar. In case of the sample sites in the main channel of the Nakdong River (N1-N4), however, the difference in the $\beta$ values within the channel tended to slightly decrease compared with the case from the maximum likelihood estimation.

\section{Testing proposed SADs for chironomids}

Considering the unique position of chironomids in benthic macroinvertebrate communities, the selected models were specifically tested using Chironomidae. At unpolluted sites, the deduced decay (DD) model tended to slightly overestimate the species numbers, however, the model appeared to be most suitable for field data compared to the other models (Fig. 4). The random fraction (RF) and random assortment (RA) tended to underestimate the values of species numbers at unpolluted sites (Fig. 4). The DD model tended to overestimate the number of species for the low ranking (i.e. low abundance) species (e.g., sites S3, D1, O1). The results from RF and RA models showed the increase in discrepancy as the rank decreased (right side on the $x$ axis in the figure).

At intermediate to highly polluted sites, however, the suitability of the models appeared to change. At intermediate pollution level the distance between the field data and model results were similar. The DD models tended to 


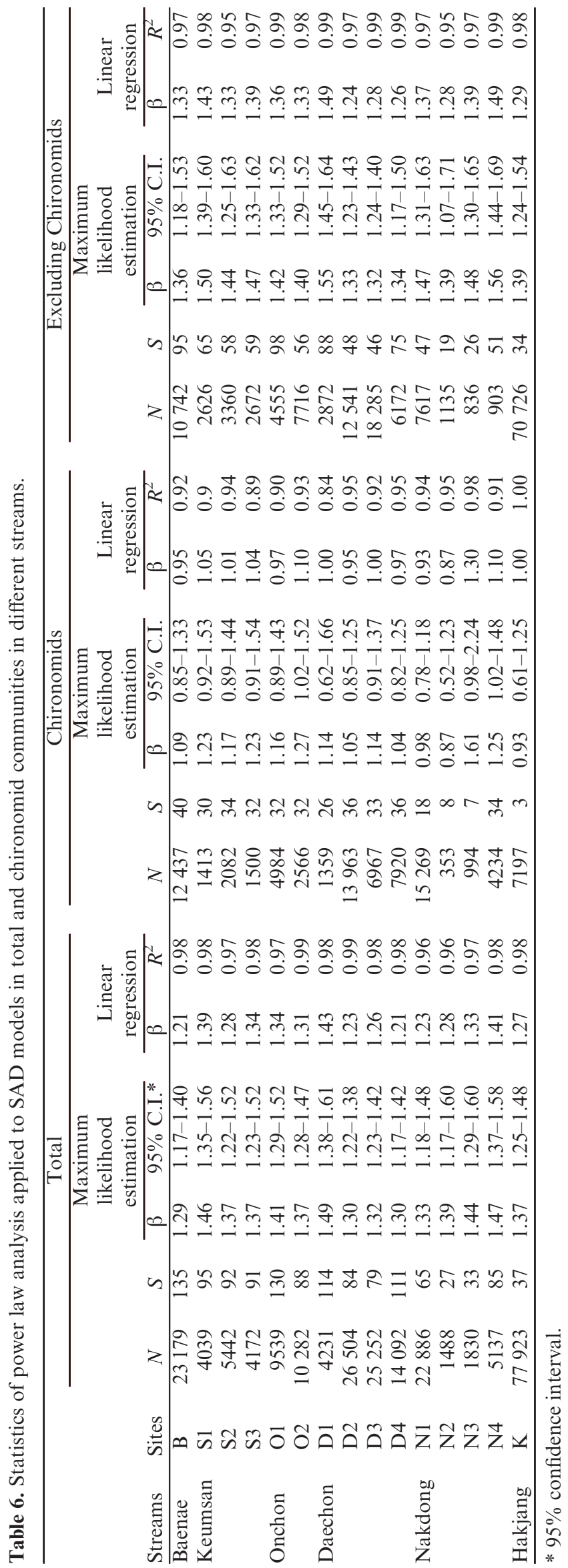

overestimate the species numbers, while the RF and RA models underestimated the value similar to what is shown in the DD model results. For the RF and RA models, however, one case matched well to field data (i.e., site $\mathrm{O} 2$ ), while the DD model still overestimated at this sample site (Fig. 4).

At highly polluted sites, the RF and RA models appeared to be more suitable for the field data than the DD model. While the DD model still overestimated the number of species at most sample sites, the RF and RA models were closer to the field data as shown at site N2 (Fig. 4). At site N4, however, results from all models did not agree with the field data. At the severely polluted site, $\mathrm{K}$, the three models were similar with each slightly overestimating the number of individuals of the secondary dominant species. The number of species was exceptionally low in this case, and results may need confirmation from more sample sites in similar conditions (Fig. 4). The relative abundance obtained from the RF and RA models were similar across the different levels of pollution.

\section{Discussion}

Our results demonstrated that SADs as applied to both total macroinvertebrates and chironomids could efficiently reveal structural changes in communities in response to disturbance. The distinctive appearance of dominant species (Table 3) was in accordance with previous studies defining the indicator groups as they relate to the different habitat conditions (Saether, 1979; Wiederholm, 1980; Hellawell, 1986; Calle-Martinez and Casas, 2006; Penczak et al., 2006; Rossaro et al., 2006; Carew et al., 2007). For both total and chironomid communities the log normal model appeared most suitable. Although this model would not identify the dynamic processes in community development, the model was confirmed again to be widely fitted to field data (Diserud and Engen, 1999; Magurran, 2004; May et al., 2007).

In the study of chironomids, identification of all specimens is a problematic issue. The collection of chironomids required a dense mesh $100-200 \mu \mathrm{m}$ in size and numerous small-sized individuals are frequently collected, while missing some small individuals is unavoidable (Storey and Pinder, 1985; Tokeshi, 1995). Although chironomid larvae play an important role in the benthic fauna, taxonomic difficulty often forces the investigators to treat them at higher levels, most often covering the (sub)-family or tribe (Armitage and Blackburn, 1985; Hilsenhoff, 1988), genus (Balloch et al., 1976; Warwick, 1993), or uncertain classified species (Kwon and Chon, 1991; Youn and Chon, 1999).

Since application of the truncated log normal distribution assumes insufficient sampling of rare species, the model was suitable for checking the SADs in chironomids. Overall fitting to log normal distribution in total communities and the selected acceptance with the geometric and $\log$ series were generally in accordance with results from Qu et al. (2008). 


\section{Pollution level}

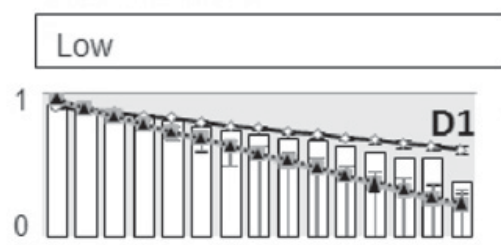

$\begin{array}{llllllllll}1 & 2 & 3 & 4 & 5 & 6 & 7 & 8 & 9 & 101112131415\end{array}$

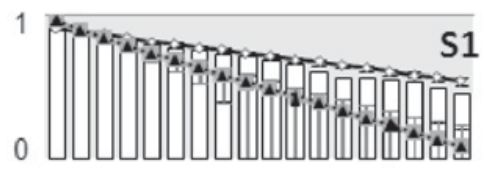

123456789101112131415161718

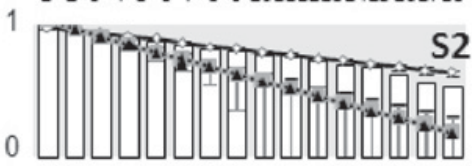

12345678910111213141516

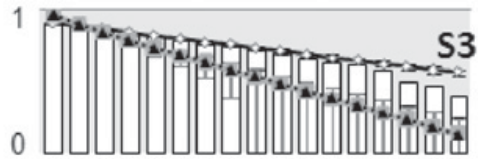

12234567891011121314151617
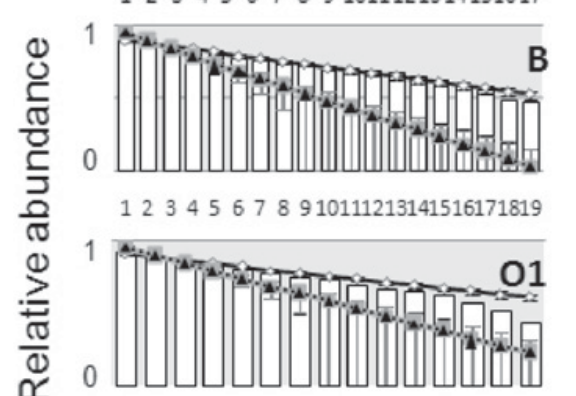

12230455677899101112131415
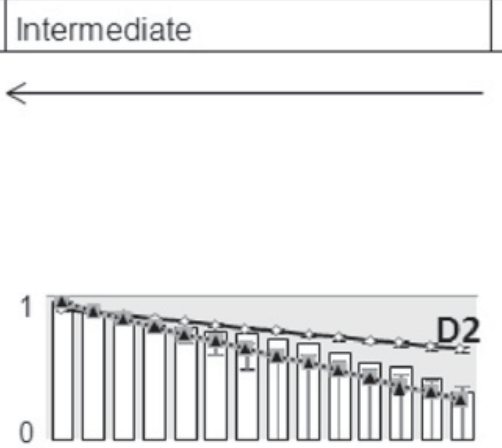

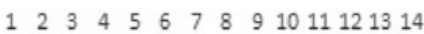

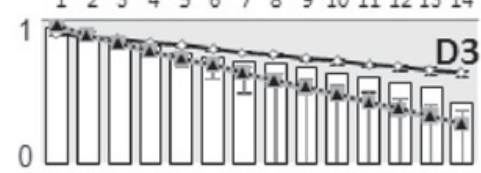

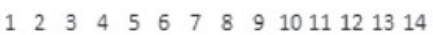

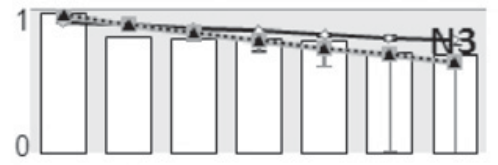

$\begin{array}{lllllll}1 & 2 & 3 & 4 & 5 & 6 & 7\end{array}$

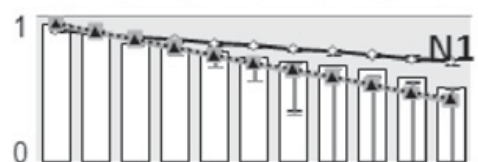

$\begin{array}{lllllllllll}1 & 2 & 3 & 4 & 5 & 6 & 7 & 8 & 9 & 10 & 11\end{array}$

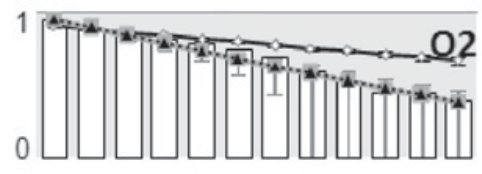

$\begin{array}{llllllllllll}1 & 2 & 3 & 4 & 5 & 6 & 7 & 8 & 9 & 10 & 11 & 12\end{array}$

Species rank

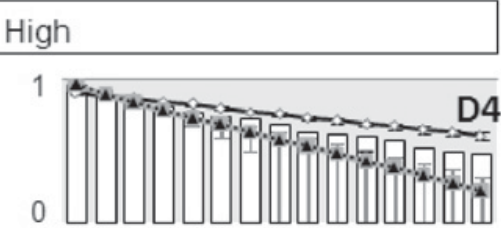

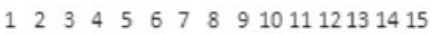
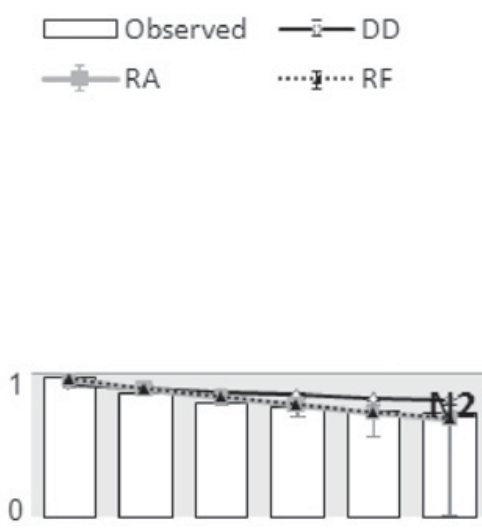

$\begin{array}{llllll}1 & 2 & 3 & 4 & 5 & 6\end{array}$

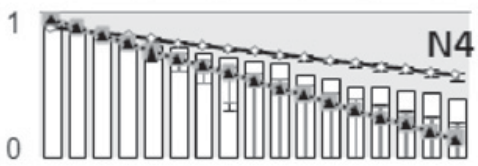

1234567891011121314151617

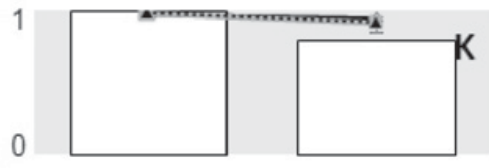

1

2

Fig. 4. Comparison of SAD models applied to abundance (normalized) in relation to the rank of species in chironomid communities across different levels of pollution in streams. Low, intermediate, and high and severe levels in pollution (vertical bars shown with the model curves indicating 95\% confidence intervals).

This study also showed that the parameters in the log normal distribution would present the structural differences in communities responding to pollution. The $\gamma$ values in the log normal model tended to increase for polluted sites in both total and chironomid communities. The increase in $\gamma$ values implied that the tolerant species were selectively adapted to polluted conditions and became increasingly dominant. Consequently, the tendency for dominancy would be stronger at polluted sites as increase in the $\gamma$ values suggested.

The structural difference between the total benthic macroinvertebrates and chironomid communities in the richness-abundance (in octave) relationships may have originated from sample collection issues (Fig. 3). The species number was characteristically high for the low abundance in the total communities. In total communities, there are numerous taxa besides Chironomidae, and there would be a higher chance of rare species being present. Drifting would be a source of rare species in streams. Trichoptera, especially Hydropsychidae, were most frequently collected in small numbers (1-2 individuals) over a broad range at unpolluted sites. Ephemeroptera, including Ephemeridae and Ephemerellidae, were also often observed at the intermediately and highly polluted sites in minimal numbers. Considering that these species in Ephemeroptera and Trichoptera are usually found in unpolluted areas, the species may have drifted down from upstream and could contribute to the increase in number of species with low numbers in total communities (Fig. 3). At polluted sites, the species from upstream were also found in low abundance including 1-2 rare species from the Ephemeroptera, Diptera and Trichoptera. Besides insect species, species in Hirudinea were also widely collected in minimal numbers from intermediate to extremely polluted sites. 
In this study, $\beta$ values in the Power analysis were not highly variable between the different levels of pollution. In Qu et al. (2008), the $\beta$ values increased at recovering sites. The parameters were measured at one site at different times in this case, reflecting the recovery of water quality. In this study, however, this type of parameter change was not observed. The $\beta$ values may be variable depending upon the diversity of habitat conditions at sample sites. More consideration is needed to check community response and the scale free structure in communities in the future.

The change in suitability of the DD, RF and RA models to different levels of pollution was also noticeable. While the DD model was more fitted to unpolluted sites, the RF and RA models tended to be more suitable for polluted sites (Fig. 4). This indicated that random effects would play an important role in disturbing conditions. Tokeshi (1987) also mentioned that random effects would contribute greatly in determining species abundance of chironomids. At site site N4 (also highly polluted), however, all the models did not fit the field data (Fig. 4). Communities collected at N4 were exceptional. Some species with the lower modal octave in individual curves were more frequently collected and consequently the octave for $\mathrm{R}_{\mathrm{N}}$ was lower than the octave for $\mathrm{R}_{\max }$ : about eight species with lower octave (17-32 individuals. $\mathrm{m}^{-2}$ ) including Chironomus flaviplumus, Cryptochironomus rostratus and Tanytarsus mendax were abundantly collected at N4. In this case $R_{\max }$ usually belonging to the octave was 33-64 individuals. ${ }^{-2}$. This contributed to a decrease in the $\gamma$ values (Table 5), indicating that some species ranked at low-intermediate levels were abundantly collected. This type of species distribution was not suitable for applying the proposed SAD models for chironomids.

The DD model, however, was useful at unpolluted sites. In this case the degree of niche preemption may be not strong since the DD model supports negation of dominance (Tokeshi, 1990). This indicated that dominancy was unfavorable and niche division occurred for the most dominant species. Futher research is required in checking how the subdivision pattern of niche will occur in aquatic conditions in this study. In fact, a wide variety of SAD models have been proposed including random fraction or assortment (Tokeshi, 1990, 1993, 1999; Fesl, 2002), log series (Ruse, 1995), geometric series (Dimitriadis and Cranston, 2007). This indicated that chironomid communites would show diverse SAD patterns in adapting to competition for resources and for environmental disturbances at study sites. Our study confirmed a wide variety in SADs, including the DD model adaptable to unpolluted sites. The mechanism of niche sharing among the residing species, however, needs to be further considered.

\section{Conclusions}

Comparative studies on SADs between total macroinvertebrates and chironomids were useful in revealing structural properties in communities responding to disturbance. The number of rare species was relatively higher in total communities, while the number of rare species was low and gradually increased to peak in the middle ranges of octaves in chironomid communities. Both total and chironomid communities were fitted to the log normal distribution, and the change in parameter $(\gamma)$ would be useful for community structure in diagnosing polluted sites. When the models proposed for chironomids were tested, the most suitable model was the DD model for clean conditions. The suitability changed to RF and RA models for polluted sites, indicating an increase in randomness of community establishment in disturbed conditions. Comparative studies of SADs in chironomids and macroinvertbrates would provide significant insight into changes in community structure and ecological assessment of water quality.

Acknowledgements. This study was financially supported by Pusan National University in the program, "Post-Doc. 2008". This work was supported by the Korea Research Foundation Grant funded by the Korean Government (MOEHRD) (KRF2007-313-C00748)

The first author is also indebted to Professor Ole A. Saether, Bergen Museum, Bergen University, for providing hundreds of chironomids taxonomy references, special thanks to the Dr. Les Ruse, the Environment Agency, Reading, UK, for his encouragements and for providing us with many of his publications. Many thanks to two Japanese colleagues, Dr. Hiromi Niitsuma of Shizuoka University and Dr. Tadashi Kobayashi of Kanagawa Prefecture for confirming several Tanypodinae species.

\section{References}

Aagaard K., 1986. The chironomid fauna of North Norwegian lakes, with a discussion on methods of community classification. Holarctic Ecol., 9, 1-12.

APHA, AWWA and WPCF, 1985. Standard methods for the examination of water and waste, 16 th edn., American public health association, Washington, $1268 \mathrm{p}$.

Arimoro F.O., Ikomi R.B. and Iwegbue C.M.A., 2007. Water quality changes in relation to Diptera community patterns and diversity measured at an organic effluent impacted stream in the Niger Delta, Nigeria. Ecol. Indic., 7, 541-552.

Armitage P.D. and Blackburn J.H., 1985. Chironomidae in a Pennine stream system receiving mine drainage and organic enrichment. Hydrobiologia, 121, 165-172.

Armitage P.D., Cranston P.S. and Pinder L.C.V. (eds.), 1995. The Chironomidae. The biology and ecology of non-biting midges, Chapman \& Hall, London, 572 p.

Balloch D., Davies C.E. and Jones F.H., 1976. Biological assessment of water quality in three British rivers: the North Esk (Scotland), the Ivel (England) and the Taf (Wales). Water Pollut. Control, 75, 92-114.

Barbour M.T., Gerritsen J., Griffith G.E., Frydenborg R., McCarron E., White J.S. and Bastian M.L., 1996. A framework for biological criteria for Florida streams using benthic macroinvertebrates. J. N. Amer. Benthol. Soc., 15, 185-211.

Barbour M.T., Gerritsen J., Snyder B.D. and Stribling J.B., 1999. Rapid bioassessment protocols for use in streams and 
wadeable rivers: periphyton, benthic macroinvertebrates and fish, 2nd edn., EPA 841-B-99-002, U.S. Environmental Protection Agency, Office of Water, Washington, D.C.

Begon M., Townsend C.R. and Harper J.L., 2006. Ecology: from individuals to ecosystems, 4th edn., Blackwell, Malden, $738 \mathrm{p}$.

Boerger H., 1981. Species composition, abundance and emergence phenology of midges in a brown-water stream of WestCentral Alberta, Canada. Hydrobiologia, 80, 7-30.

Calle-Martinez D. and Casas J.J., 2006. Chironomid species, stream classification, and water-quality assessment: the case of 2 Iberian Mediterranean mountain regions. J. N. Am. Benthol. Soc., 25, 465-476.

Carew M.E., Pettigrove V., Cox R.L. and Hoffmann A.A., 2007. The response of Chironomidae to sediment pollution and other environmental characteristics in urban wetlands. Freshwat. Biol., 52, 2444-2462.

Cranston P.S., 1982. A key to the larvae of the British Orthocladiinae (Chironomidae). Scientific Publications of FBA , 45, 1-152.

De Bisthoven L.J., Gerhardt A. and Soares A.M.V.A., 2005. Chironomid larvae as bioindicators of an acid mine drainage in Portugal. Hydrobiologia, 532, 181-191.

Del Moral R., 1999. Plant succession on pumice at Mount St. Helens, Washington. Am. Mid. Nat., 141, 101-114.

Dimitriadis S. and Cranston P.S., 2007. From the mountains to the sea: assemblage structure and dynamics in Chironomidae (Insecta: Diptera) in the Clyde River estuary gradient, New South Wales, southeastern Australia. Aust. J. Entomol., 46, 188-197.

Diserud O.H. and Engen S., 1999. A general and dynamic species abundance model, embracing the lognormal and the Gamma models. Am. Nat., 155, 498-511.

Epler J.H., 2001. Identification Manual for the Larval Chironomidae (Diptera) of North and South CarolinaA guide to the taxonomy of the midges of the southeastern United States, including Florida, North Carolina Department of Environment and Natural Resources, Raleigh, NC, and St. Johns River Water Management District, Palatka.

Fesl C., 2002. Niche-oriented species-abundance models: different approaches of their application to larval chironomid (Diptera) assemblages in a large river. J. Anim. Ecol., 71, 1085-1094.

Fisher R.A., Corbet A.S. and Williams C.B., 1943. The relation between the number of species and the number of individuals in a random sample of an animal population. J. Anim. Ecol., $12,42-58$.

Ford N.B. and Lancaster D.L., 2007. The species-abundance distribution of snakes in a bottomland hardwood forest of the southern United States. J. Herpetology, 41, 385-393.

Forster M.A. and Warton D.I., 2007. A metacommunity-scale comparison of species-abundance distribution models for plant communities of eastern Australia. Ecography, 30, 449-458.

Gray J.S., 1981. Detecting pollution induced changes in communities using the log-normal distribution of individuals among species. Mar. Pollut. Bull., 25, 48-50.

Gray J.S. and Mirza F.B., 1979. A possible method for the detection of pollution-induced disturbance on marine benthic communities. Mar. Pollut. Bull., 10, 142-146.

Hamerlik L. and Bitusik P., 2009. The distribution of littoral chironomids along an altitudinal gradient in High Tatra
Mountain lakes: could they be used as indicators of climate change? Ann. Limnol. - Int. J. Lim., 45, 145-156.

Hawkes H.A., 1997. Origin and Development of the Biological Monitoring Working Party Score System. Water Res., 32, 964-968.

Hellawell J.M., 1986. Biological indicators of freshwater pollution and environmental management, Elsevier, Amsterdam, $446 \mathrm{p}$.

Hilsenhoff W.L., 1988. Rapid field assessment of organic pollution with a family-level biotic index. J. N. Am. Benthol. Soc., 7, 65-68.

Hughes R.G., 1984. A model of the structure and dynamics of benthic marine invertebrate communities. Mar. Ecol. Progr., $15,1-11$.

Kawai K., Yamagishi T. and Kubo Y., 1989. Usefulness of chironomid larvae as indicators of water quality. Jpn. J. Sanitation. Zool., 40, 4, 269-283.

Klink A.G. and Moller Pillot H.K.M., 2003. Chironomidae larvae - Key to the higher taxa and species of the lowlands of Northwestern Europe, World Biodiversity Database CD-ROM series, ETI, Amsterdam.

Kwak I.-S., Liu G.C., Park Y.-S., Song M.-Y. and Chon T.-S., 2002. Characterization of benthic macroinvertebrate communites and hydraulic factors in small-scale habitats in a polluted stream. Korean J. Limnol., 35, 295-305.

Kwon T.-S. and Chon T.-S., 1991. Ecological studies on benthic macroinvertebrates in the Suyong River - II. Investigations on distribution and abundance in its main stream and four tributaries. Korean J. Limnol., 24, 179-198.

Langton P.H. and Visser H., 2003. Chironomidae exuviae A key to pupal exuviae of the West Palaearctic Region, Biodiversity Center of ETI, Amsterdam, CD-ROM.

Lods-Crozet B., Vencioni V., Olafsson J.S., Snook D.L., Velle G., Brittain J.E., Castella E. and Rossaro B., 2001. Chironomid (Diptera: Chironomidae) communities in six European glacier-fed streams. Freshwat. Biol., 46, 1791-1809.

Magurran A.E., 1988. Ecological diversity and its measurement. Chapman \& Hall, London, 179 p.

Magurran A.E., 2004. Measuring biological diversity, Blackwell, Oxford, $256 \mathrm{p}$.

Magurran A.E. and Henderson P.A., 2003. Explaining the excess of rare species in natural species abundance distributions. Nature, 422, 714-716.

May R.M., 1975. Patterns of species abundance and diversity. In: Cody M. and Diamond J.M. (eds.), Ecology of species and communities, Harvard University Press, Cambridge, 81-120.

May R.M. and McLean A.R. (eds.), 2007. Theoretical ecology: Principles and applications, Oxford University Press, Oxford, $257 \mathrm{p}$.

May R.M., Crawley M.J. and Sugihara G., 2007. Communities: patterns. In: May R.M. and McLean A.R. (eds.), Theoretical ecology: principles and applications, Oxford University Press, Oxford, 111-131.

McGill B.J., Etienne R.S., Gray J.S., Alonso D., Anderson M.J., Benecha H.K., Dornelas M., Enquist B.J., Green J.L., He F.L., Hurlbert A.H., Magurran A.E., Marquet P.A., Maurer B.A., Ostling A., Soykan C.U., Ugland K.I. and White E.P., 2007. Species abundance distribution: moving beyond single prediction theories to integration within an ecological framework. Ecol. Lett., 10, 995-1015.

Motomura I., 1932. On the statistical treatment of communities. Zool. Manage., Tokyo, 44, 379-383. 
Niitsuma H. and Yamamoto M., 2005. Chironomidae. In: Kwai T. and Tanida K. (eds.), Aquatic insects of Japan: Manual with keys and illustrations, Tokai University Press, Kanagawa, 1035-1185.

Oh Y.-N. and Chon T.-S., 1991a. A study on the benthic macroinvertebrates in the middle reaches of the Paenae stream, a tributary of the Nakdong River, Korea. I. Community analysis and biological assessment of the water quality. Korean J. Ecol., 14, 345-360.

Oh Y.-N. and Chon T.-S., 1991b. A study on the benthic macroinvertebrates in the middle reaches of Paenae stream, a tributary of the Naktong River, Korea. II. Comparison of communities and environments at the upper and lower sites of levees. Korean J. Ecol., 14, 399-413.

Oh Y.-N. and Chon T.-S., 1993. A study on the benthic macroinvertebrates in the middle reaches of Paenae stream, a tributary of the Naktong River, Korea III. Drifting aquatic insects in four seasons. Korean J. Ecol., 16, 489-499.

Penczak T., Kruk A., Grzybkowska M. and Dukowsaka M., 2006. Patterning of impoundment impact of chironomid assemblages and their environment with use of the selforganizing map (SOM). Acta Oecol., 30, 312-321.

Pinder L.C.V., 1986. Biology of freshwater Chironomidae. Аnnu. Rev. Entomol., 31, 1-23.

Preston F.W., 1948. The commonness and rarity of species. Ecology, 29, 254-283.

Pueyo S., 2006a. Self-similarity in species-area relationship and in species abundance distribution. Oikos, 112, 156-162.

Pueyo S., 2006b. Diversity: between neutrality and structure. Oikos, 112, 392-405.

Qu X.D., Song M.-Y., Park Y.-S., Oh Y.-N. and Chon T.-S., 2008. Species abundance patterns of benthic macroinvertebrate communities in polluted streams. Ann. Limnol. - Int. J. Lim., 44, 119-133.

Rabeni C. and Wang N., 2001. Bioassessment of streams using macroinvertebrates: Are the Chironomidae necessary? Environ. Monit. Assess., 71, 177-185.

Raunkiaer C., 1909. Formationsundersogelse og Formationsstatistik. Botanisk Tidskrift, 30, 20-132.

Raposeiro P.M., Hughes S.J. and Costa A.C., 2009. Chironomidae (Diptera: Insecta) in oceanic islands: New records for the Azores and biogeographic notes. Ann. Limnol. - Int. J. Lim., 45, 59-67.

Ree H.I. and Kim H.S., 1981. Studies on Chironomidae (Diptera) in Korea. I. Taxonomical study on adults of Chironomidae. Proc. Coll. Nat. Sci., SNU, 6, 123-226.

Resh V.H. and Jackson J.K., 1993. Rapid assessment approaches to biomonitoring using benthic macroinvertebrates. In: Rosenberg D.M. and Resh V.H. (eds.), Freshwater biomonitoring in benthic macroinvertebrates, Chapman \& Hall, New York, 195-233.

Resh V.H. and Rosenberg D.M. (eds.), 1984. The ecology of aquatic insects, Praeger, New York, 625 p.

Rosenberg D.M., 1993. Freshwater biomonitoring and Chironomidae. Neth. J. Aquat. Ecol., 26, 101-122.

Rossaro B., Lencioni V., Boggero A. and Marziali L., 2006. Chironomids from Southern Alpine running waters: ecology, biogeography. Hydrobiologia, 562, 231-246.

Rossaro B., Marziali L., Cardoso A.C., Solimini A., Free G. and Giacchini R., 2007. A biotic index using benthic macroinvertebrates from Italian lakes. Ecol. Indic., 7, 412-429.
Ruse L.P., 1995. Chironomid community structure deduced from larvae and pupal exuviae of a chalk stream. Hydrobiologia, 315, 135-142.

Saether O.A., 1975. Nearctic chironomids as indicators of lake typology. Verhangen Int. Verein Limnol., 19, 3127-3133.

Saether O.A., 1979. Chironomid communities as water quality indicators. Holarctic Ecol., 2, 65-74.

Sasa M., 1979. A morphological study of adults and immature stages of 20 Japanese species of the family Chironomidae (Diptera). Research Report of NIES, 7, 1-148.

Sasa M., 1984. Studies on chironomid midges in lakes of the Nikko National Park. Pt. II. Taxonomical and morphological studies on the chironomid species collected from lakes in the Nikko National Park. Research Report of NIES, 70, 16-215.

Sasa M. and Kikuchi M., 1995. Chironomidae (Diptera) from Japan, University of Tokyo Press, Tokyo, 333 p.

Schmid P.E., 1992. Community structure of larval Chironomidae in a backwater area of the River Danube. Freshw. Biol., 27, 151-167.

Sokal R.R. and Rohlf F.J., 1995. Biometry: the principles and practice of statistics in biological research, 3rd edn., W.H. Freeman and Company, New York, 887 p.

Song M.-Y., Lee S.-E., Park J.-I., Kim B.-H., Koh S.-C., Lee K.-S., Park Y.-S. and Chon T.-S., 2005. Comparative community analysis of benthic macroinvertebrates and microorganisms across different levels of organic pollution in a stream by using artificial neural networks. WSEAS Trans. Biol. Biomed., 3, 257-268.

Storey A.W. and Pinder L.C.V., 1985. Mesh-size efficiency of sampling of larval Chironomidae. Hydrobiologia, 124, 193197.

Syrek D., Weiner W.M., Wojtylak M., Olszowska G.Y. and Kwapis Z., 2006. Species abundance distribution of collembolan communities in forest soils polluted with heavy metals. Appl. Soil Ecol., 31, 239-250.

Tang H.Q., 2006. Biosystematic study on the chironomid larvae in China (Diptera, Chironomidae), Ph.D. Thesis, Nankai University, $945 \mathrm{p}$.

Tokeshi M., 1990. Niche apportionment or random assortment: species abundance patterns revisited. J. Anim. Ecol., 59, $1129-1146$.

Tokeshi M., 1993. Species abundance patterns and community structure. Adv. Ecol. Res., 24, 111-186.

Tokeshi M., 1995. Species interactions and community structure. In: Armitage P.D., Cranston P.S. and Pinder L.C.V. (eds.), The Chironomidae: biology and ecology of non-biting midges, Chapman \& Hall, London, 297-335.

Tokeshi M., 1999. Species Coexistence: Ecological and Evolutionary Perspectives, Blackwell Science, Oxford, 454 p.

Tokeshi M. and Townsend C.R., 1987. Random patch formation and weak competition: coexistence in an epiphytic chironomid community. J. Anim. Ecol., 56, 833-845.

Warwick W.F., 1993. The effect of trophic/contaminant interactions on Chironomid community structure and succession (Diptera, Chironomidae). Neth. J. Aquat. Ecol., 26, 563-575.

Wiederholm T., 1980. Use of benthos in lake monitoring. J. Water Poll. Control Federation, 52, 537-547.

Wiederholm T. (ed.), 1983. Chironomidae of the Holarctic region. Keys and Diagnoses. Part 1. Larvae. Entomol. Scand. Suppl., 19, 1-457. 
Wiederholm T. (ed.), 1986. Chironomidae of the Holarctic region. Keys and Diagnoses. Part II. Pupae. Entomol. Scand. Suppl., 28, 1-482.

Wilson R.S. and Ruse L.P., 2005. A guide to the identification of genera of chironomid pupal exuviae occurring in Britain and Ireland (including common genera from Northern Europe) and their use in monitoring lotic and lentic freshwater, Freshwater Biological Association, Special Publication, No. 13, The Ferry House, Far Sawrey, Ambleside, Cumbria.

Youn B.-J. and Chon T.-S., 1999. Effects of the pollution on communities of Chironomidae (Diptera) in the Soktae Stream a tributary of the Suyong River. Korean J. Limnol., $32,24-34$. 